\title{
Recurrent cornual pregnancy: a case report
}

\author{
Neelotparna Saikia*, Sukalyan Halder, Punam Jain
}

Department of Obstetrics and Gynecology, Nazareth Hospital, Shillong, Meghalaya, India

Received: 19 June 2021

Accepted: 13 July 2021

\section{*Correspondence:}

Dr. Neelotparna Saikia,

E-mail: neelots@gmail.com

Copyright: (C) the author(s), publisher and licensee Medip Academy. This is an open-access article distributed under the terms of the Creative Commons Attribution Non-Commercial License, which permits unrestricted non-commercial use, distribution, and reproduction in any medium, provided the original work is properly cited.

\begin{abstract}
Cornual ectopic pregnancy accounts for $2-4 \%$ of all the ectopic pregnancies with a mortality rate 6-7 times higher than that of the ectopics in general. It is a diagnostic and therapeutic challenge to the clinician with a significant risk of rupturing and bleeding. As of yet, the incidence of recurrent cornual ectopic pregnancies is unknown. This report described the case of a patient who developed two cornual ectopic pregnancies within a span of 3 years with an intervening full term normal vaginal delivery. The 1st cornual ectopic was successfully managed by laparoscopic resection, which was followed by an uneventful postoperative course. The following contralateral cornual ectopic was managed by laparotomy since the patient presented with large hemoperitoneum.
\end{abstract}

Keywords: Cornual pregnancy, Laparoscopy, Recurrent

\section{INTRODUCTION}

Cornual or interstitial region of the fallopian tube lies within the muscular wall of the uterus. It measures $1-2 \mathrm{~cm}$ with a diameter of $0.7 \mathrm{~mm}$ with a slightly tortuous course extending obliquely upwards and outwards from uterine cavity. ${ }^{1}$ This section of tube is relatively thick, and it is located in highly vascular region. Therefore, cornual ectopic pregnancy tends to rupture later, with more severe bleeding than those of other ectopic pregnancies. Cornual ectopic pregnancy is a life-threatening complication especially if it ruptures before diagnosis and causes significant intraperitoneal bleeding leading to hypovolemia and shock.

Rudimentary horn, previous ipsilateral salpingectomy or ectopic pregnancy, proximal intratubal adhesions and in vitro fertilization are factors predisposing for this clinical entity. ${ }^{2,3}$ Incidence of recurrent cornual ectopic is not known. The three sonographic criteria for diagnosis of a cornual ectopic pregnancy as described in a previous study are: (a) an empty uterine cavity; (b) a chorionic sac seen separately and at least $1 \mathrm{~cm}$ from the lateral edge of uterine cavity; and (c) a thin $(<5 \mathrm{~mm})$ myometrial layer surrounding the gestational sac. ${ }^{4}$ The uterine musculature integrity is reduced after a cornual ectopic pregnancy, thus increasing the risk of uterine rupture or scar dehiscence in subsequent pregnancies. ${ }^{5}$

\section{CASE REPORT}

Mrs X, a 26-years-old G2P1L1 with h/o 2 months of amenorrhoea came to the emergency with complaints of bleeding per vaginum for 1 day. She did not have any complain of pain in abdomen. Patient had past history of tuberculosis and received ATT. On examination, her vitals were stable. On per abdomen examination, it was soft and non-tender. On per vaginum examination, uterus was 8week size with evidence of mild dark altered bleeding. There was no forniceal or cervical motion tenderness. USG done showed bulky right ovary with no evidence of intrauterine G-sac and ET being $8 \mathrm{~mm}$.

Serum beta HCG was $17,850 \mathrm{mIU} / \mathrm{ml}$. Patient was counselled about the possibility of ectopic pregnancy and was kept for observation. Serial serum beta HCG done showed a plateauing trend. Repeat USG after 4 days showed right cornual ectopic pregnancy with a $10 \mathrm{~mm} \mathrm{G}-$ sac in the right cornu surrounded by myometrium measuring $6 \mathrm{~mm}$. patient was then taken up for exploratory 
laparoscopy. Intra-operatively, a right sided cornual ectopic pregnancy noted. Right cornual excision with partial right salpingectomy was done. Repair of cornual end with endo suturing was done followed by diathermy with ligasure to achieve haemostasis. The patient had an uneventful post-operative period and was discharged after few days.

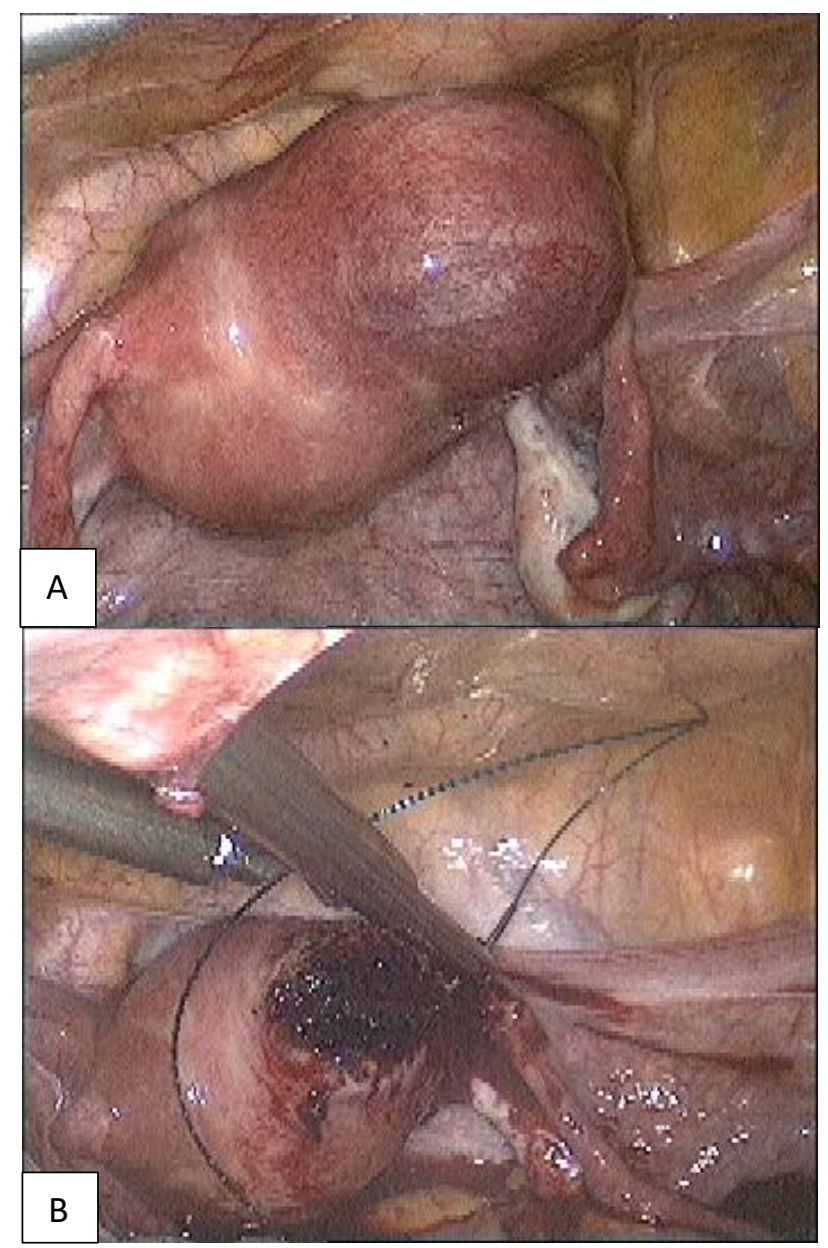

Figure 1: (A) Right cornual ectopic; (B) Endosuturing being done after resection of cornual ectopic.

3 years later, the same patient presented in the emergency with c/o pain in abdomen for 1 day. She did not remember her LMP, hence amenorrhoea could not be ruled out. UPT done was positive. From her previous records we found out that patient had a full term normal vaginal delivery at 37 weeks of gestation, 1 year after the first cornual ectopic pregnancy. Clinically the patient looked pale and had tachycardia. On examination, diffuse tenderness was elicited all over abdomen.

On per vaginum examination, uterus was anteverted and bulky. Cervical motion tenderness with posterior forniceal tenderness was evident but no bleeding was noted. Pouch of Douglas was obliterated and bilateral fornices were full. USG done showed moderate to large hemoperitoneum with left tubal ectopic pregnancy at $6+3$ weeks of gestation with regular cardiac activity. Patient was taken up for emergency laparotomy. Intraoperatively a large hemoperitoneum of approximately 21 was noted with left sided ruptured cornual ectopic pregnancy. Cornual resection and partial left salpingectomy was done. She received 2 units of whole blood transfusion. Patient had an uneventful post-operative period.

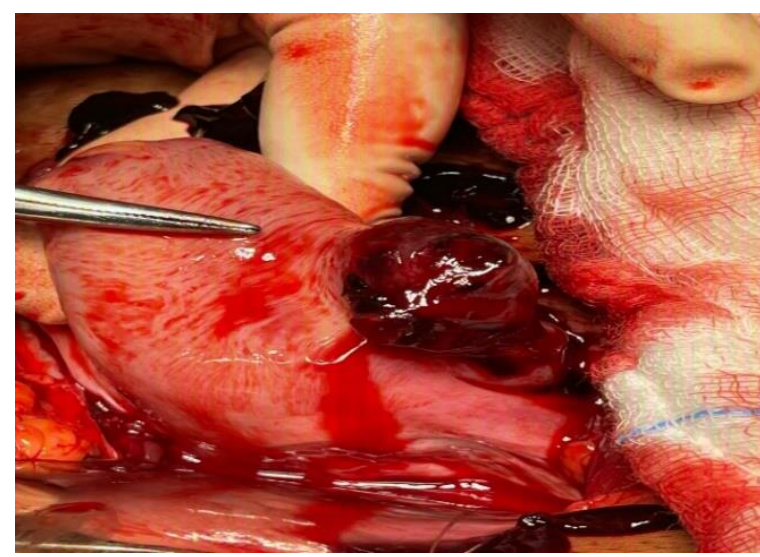

Figure 2: Left sided ruptured cornual ectopic pregnancy.

\section{DISCUSSION}

In cornual pregnancy, the embryo is implanted lateral to the round ligament while in angular pregnancy, the embryo is implanted in the lateral angle of the uterine cavity, medial to the uterotubal junction and round ligament. ${ }^{1}$

Cornual ectopic pregnancies are difficult to diagnose early and have the potential to progress into the second trimester due to the rich blood supply from branches of the uterine and ovarian vessels in addition to distensible myometrium surrounding the pregnancy. The consequences are often catastrophic in case of uterine rupture with profuse intraperitoneal bleeding. Management of cornual ectopic pregnancies is another area of difficulty. Medical management with methotrexate has reported failure rates of up to $35 \%$ with better success rates $(72-95 \%)$ with surgical modalities. ${ }^{7}$

However, surgical management does not offer protection against recurrent cornual pregnancies. Other forms of medical management which are available include local injection of methotrexate, potassium chloride or prostaglandins under ultrasound, hysteroscopic or laparoscopic guidance. ${ }^{4}$ Cornual ectopic pregnancy carries a significant mortality rate of $2-2.5 \%$ and accounts for $20 \%$ of all deaths due to ectopic pregnancies. ${ }^{6}$ The successful vaginal delivery in this particular patient after undergoing laparoscopic resection of cornual ectopic demonstrates the ability of the myometrium to remodel and undergo physiological changes during a pregnancy in the same way as after a myomectomy or caesarean section. However, the risk of rupture, particularly during labour, remains high. 
Also, recurrence of cornual ectopic on the ipsilateral or on contralateral side as in this patient is also a rare event and the incidence remains unknown as of yet.

\section{CONCLUSION}

Cornual ectopic pregnancy is a rare yet potentially lifethreatening form of ectopic pregnancy. It poses a significant diagnostic and a therapeutic challenge. Hence, high index of suspicion supplemented with modern diagnostic tools is essential for early diagnosis. Patient needs to be counselled for her future fertility problems and risk of rupture of uterus in subsequent intrauterine pregnancy. We propose that appropriate follow-up should be routinely undertaken following treatment of cornual ectopic pregnancy in those women who intend to have further pregnancies.

\section{Funding: No funding sources}

Conflict of interest: None declared

Ethical approval: Not required

\section{REFERENCES}

1. Velayudam DA, Prabhu RB, Devi DL, Meenalochani $\mathrm{P}$, Gutgutia I. Recurrent cornual ectopic pregnancy-A case report. Int J Med Res Health Sci. 2015;4(4):91920.
2. Chopra S, Keepanasseril A, Rohilla M, Bagga R, Kalra J, Jain V. Obstetric morbidity and the diagnostic dilemma in pregnancy in rudimentary horn: retrospective analysis. Archives Gynecol Obstet. 2009;280(6):907-10.

3. Pluchino N, Ninni F, Angioni S, Carmignani A, Genazzani AR, Cela V. Spontaneous cornual pregnancy after homolateral salpingectomy for an earlier tubal pregnancy: a case report and literature review. J Minimally Invasive Gynecol. 2009;16(2):208-11.

4. Tritsch IE, Monteagudo A, Matera C, Veit CR. Sonographic evolution of cornual pregnancies treated without surgery. Obstet Gynecol. 1992;79(6):1044-9.

5. Maruthini D, Sharma V. A case of live birth after uterine reconstruction for recurrent cornual ectopic pregnancy following IVF treatment. Case Report Obstet Gynecol. 2013;625261.

6. Sahoo S, Jose J, Shah N, Opemuyi I. Recurrent cornual ectopic pregnancies. Gynecol Surg. 2009;6(4):389-91.

7. Canis M, Savary D, Pouly JL, Wattiez A, Mage G. Ectopic pregnancy: criteria to decide between medical and conservative surgical treatment?. J Gynecol Obstet Biol Reprod. 2003;32(7):54-63.

Cite this article as: Saikia N, Halder S, Jain P.

Recurrent cornual pregnancy: a case report. Int J Reprod Contracept Obstet Gynecol 2021;10:3229-31. 